une revue Gallia

Rhône-Alpes | 2007

\title{
Le Poët-Clard
}

Château Saint-André

Sylvie Bocquet

\section{(2) OpenEdition}

Édition électronique

URL : http://journals.openedition.org/adlfi/6887

ISSN : 2114-0502

Éditeur

Ministère de la culture

Référence électronique

Sylvie Bocquet, « Le Poët-Clard », ADLFI. Archéologie de la France - Informations [En ligne], Rhône-Alpes, mis en ligne le 01 mars 2007, consulté le 27 avril 2019. URL : http://journals.openedition.org/ adlfi/6887

Ce document a été généré automatiquement le 27 avril 2019

(c) Ministère de la Culture et de la Communication, CNRS 


\title{
Le Poët-Clard
}

\author{
Château Saint-André
}

\section{Sylvie Bocquet}

\section{Identifiant de l'opération archéologique : 229380}

Date de l'opération : 2007 (EX)

1 Le diagnostic mené sur les aménagements extérieurs du château Saint-André, au PoëtCélard, s'inscrit à la fin de la campagne de restauration de l'édifice (parcelle B 499).

2 Occupant un replat en partie artificiel de $600 \mathrm{~m}$ d'altitude, en aval d'une colline et face à un panorama dégagé sur les montagnes Saoû et de Couspeau, le site classé Monument historique regroupe un bâtiment principal de plan quadrangulaire flanqué de trois tours d'angles ainsi que des dépendances (anciennes écuries, lavoir, potager, pigeonnier, granges). Il s'agit d'une reconstruction moderne (XVI ${ }^{\mathrm{e}}$ s., XVII ${ }^{\mathrm{e}}$ s. puis XVIIle s.), succédant à un édifice antérieur, mal connu (XlV $\mathrm{e}$ s. ?).

3 Six sondages, totalisant une surface d'étude de $167,32 \mathrm{~m}^{2}(9,6 \%$ de l'emprise du diagnostic), ont été répartis dans la cour intérieure (sondage 1$)$, sur la terrasse du château (sondages 2, 3 et 4) et dans le pré au nord des dépendances (sondages 5 et 6 ).

4 Une partie de la topographie du secteur s'observe dans les coupes stratigraphiques des sondages 1,3 et 4 . Le terrain naturel - un sable argileux brun-vert issu de la décomposition $\mathrm{du}$ socle de grès sous-jacent - se repère, d'ouest en est, à 598,80 m d'altitude, à 598,58 m (sondage 1), à 598,28 m (sondage 3) et à 597,42 m (sondage 4).

Dans le sondage 1 traversant la cour intérieure, un massif maçonné large de 3,50 m (arasé à 598,60 m d'altitude) pourrait appartenir à un état antérieur aux aménagements actuellement conservés (XVI $\mathrm{s}$. - XVII ${ }^{\mathrm{e}}$ s. et XVIIle $\mathrm{s}$.). Il n'est pas identifié, en raison de l'exiguïté de l'emprise d'observation, mais comprend peut-être un ancien seuil (à 598,58 m d'altitude). En avant de la façade est, une étroite maçonnerie, orientée nordsud, lui est peut-être contemporaine. 
6 Dans le sondage 2, une tour circulaire possédant un diamètre extérieur compris entre 3,20 $\mathrm{m}$ et $3,60 \mathrm{~m}$ (surface intérieure : $2,30 \mathrm{~m}^{2}$ ), semble constituer une construction isolée, distante de $6 \mathrm{~m}$ de la façade orientale du château (sommet : 598,32 $\mathrm{m}$ d'altitude). S'agit-il d'un dispositif d'entrée ou d'approche du bâtiment principal, d'un bâtiment utilitaire de type communs? Pour Joëlle Tardieu (SRA), il pourrait s'agir d'aménagements du jardin moderne.

7 Au nord, un mur maçonné et un sol pavé (à 597,57 m d'altitude) signalent un espace orienté perpendiculairement à la façade du château (bâtiment semi-enterré (?), accolé à la façade est et communiquant avec la pièce nord-est du logis nord ?).

8 Ces maçonneries, non datées, sont scellées par des remblais du XIX ${ }^{\mathrm{e}} \mathrm{s}$. puis du XX $\mathrm{X}^{\mathrm{e}}$., perturbant la reconnaissance d'éventuels plantations ou aménagements de jardins anciens.

9 Le sondage 3 révèle un bâtiment maçonné de plan circulaire ( $5 \mathrm{~m}$ de diamètre intérieur), dont la construction reste non datée, au sol pavé de galets et de petits moellons de grès soigneusement agencés. Au centre supposé de la pièce, une base moulurée de colonne remployée participe au support de la couverture de ce petit édifice (comprenant un unique niveau ?), peut-être à vocation agricole.

10 Après son abandon, au XIX ${ }^{\mathrm{e}}$ s., un sol pavé irrégulier présentant une pente ouest-est, marque l'aménagement de la terrasse, ou d'un chemin entre le château et les dépendances.

11 Retenons qu'aucun mobilier - céramique ou autre - du Moyen Âge central et des périodes antérieures n'a été recueilli lors de ce diagnostic. L'occupation du site semble conditionnée par la présence du château ou plutôt de la maison forte.

\section{INDEX}

Index chronologique : ép contemporaine, ép médiévale, Temps Modernes, XIVe siècle apr. J.-C., XVIe siècle apr. J.-C., XVIIe siècle apr. J.-C., XVIIIe siècle apr. J.-C.

Index géographique : Rhône-Alpes, Drôme, Poët-Célard

operation expertise (EX)

\section{AUTEURS}

SYLVIE BOCQUET 